\title{
MEMBRAN PROSESLER İLE MEZBAHA ATIKSULARININ ARITIMI
}

\author{
Öznur Begüm GÖKÇEK'1[ \\ ${ }^{1}$ Niğde Ömer Halisdemir Üniversitesi, Çevre Mühendisliği Bölümü, 51240, Niğde Türkiye
}

\begin{abstract}
ÖZET
Gıda sanayi içinde yer alan mezbaha endüstrisi, proseste kullanılan su hacmi ve kirletici konsantrasyonu bakımından oldukça önemli bir kirlilik kaynağına sahiptir. Bu atık suların arıtılması için çeşitli fiziksel, kimyasal ve biyolojik teknikler kullanılmaktadır. Bu çalışmada, suyun yeniden kullanımına olanak sağlayabilecek ileri arıtma yöntemlerinden biri olan membran arıtımı üzerine deneyler gerçekleştirilmiştir. Yapılan çalışmanın amacı; farklı basınçlardaki 2 farklı ultrafiltrasyon (UF) (10 kDA PES, $50 \mathrm{kDA}$ PAN) membranı ile nanofiltrasyon (NF) (150-300 DA) membranının gerçek mezbaha atıksuyunun arıtımındaki performanslarının değerlendirilmesi ve karşılaştırılmasıdır. Membran performansları kimyasal oksijen ihtiyacı (KOI), iletkenlik, Askıda katı madde (AKM), membran akısı ve akı kayıpları açısından değerlendirilmiştir. Yapılan deneyler neticesinde en iyi KOİ $(\% 88,75)$, iletkenlik $(\% 43,95)$ ve AKM $(\% 70,83)$ giderimi 150-300 DA NF membranda gerçekleşmiştir. 2 farklı UF membranları ile yapılan deneylerden elde edilen toplam akı kayıplarının NF membranı ile elde edilen toplam akı kayıplarından daha yüksek olduğu belirlenmiştir. NF membranında 8 ve 10 barda yapılan deneylerde konsantrasyon polarizasyonundan kaynaklanan akı kaybının daha yüksek olduğu belirlenmiştir.
\end{abstract}

Anahtar kelimeler: Mezbaha atıksuyu, Membran arıtım, Nanofiltrasyon, Ultrafiltrasyon, Ak1

\section{TREATMENT OF SLAUGHTERHOUSE WASTEWATER WITH MEMBRANE PROCESSES}

\begin{abstract}
The slaughterhouse industry in the food industry has an important source of pollution in terms of water volume and concentration of pollutants used in the process. Various physical, chemical and biological techniques are used for the treatment of these wastewater. In this study, experiments on membrane treatment, which is one of the advanced treatment methods that can allow the reuse of water, have been carried out. The aim of the study; to evaluate and compare the performance of two different ultrafiltration membranes at different pressures and nanofiltration membranes in the treatment of real slaughterhouse wastewater. Membrane performances were evaluated in terms of chemical oxygen demand (COD), conductivity, suspended solids, membrane flux and flux losses. As a result of the experiments, the best COD (88.75\%), conductivity (43.95\%) and SS (70.83\%) removal was achieved in 150-300 DA NF membrane. It was determined that total flux losses obtained from experiments with 2 different UF membranes were higher than total flux losses obtained with NF membrane. Flux loss due to concentration polarization was found to be higher in experiments carried out at 8 and 10 bar in NF membrane.
\end{abstract}

Keywords: Slaughterhouse wastewater, Membrane treatment, Nanofiltration, Ultrafiltration, Flux

\section{GİRIŞ}

Endüstrileşmenin ve nüfus artışının büyük hız kazanmasıyla son yıllarda su kaynakları gün geçtikçe azalmakta ve kirlenmektedir. Farklı endüstrilerden çıkan ve deşarj edildikleri su ortamını olumsuz etkileyen atıksular, içerdikleri organik ya da inorganik maddelerden dolayı kirlenmelere ve ekolojik dengenin bozulmasına sebep olmaktadır[1]. Özellikle yüksek organik madde içeren endüstriyel atıksuların alıcı ortama verilmesiyle oluşacak zarar, bu atıksuların hacimleri ve konsantrasyonuna bağlı olarak değişmektedir. Mezbaha endüstrisi gıda sanayinde önemli bir yeri olmakla birlikte, proseste kullanılan su hacmi ve yüksek miktarlarda kirletici konsantrasyonu açısından önemli bir kirlilik kaynağıdır. Mezbaha endüstrisi atıksuyunun kalitesi; su kullanımı, kan tutma verimi, kesilen hayvan tipi ve et işleme miktarı gibi çok sayıda faktöre bağlıdır [2,3]. Mezbahalardan oluşan atıksuların arıtılmadan direkt deşarj edilerek alıcı ortama verilmesi sonucu nehirler oksijenini yitirmekte ve yüzey suları kirlenmektedir [2]. Bu nedenle, mezbaha atıksularının deşarj edilmeden önce arıtılması

* Corresponding author / Sorumlu yazar. Tel.:0 3882254018 ; e-mail / e-posta: begumgokcek@ ohu.edu.tr,

Geliş / Recieved: 06.11.2019 Kabul/ Accepted: 06.01.2020 doi: 10.28948/ngumuh.643722 
Ö. B. Gökçek

gerekmektedir [4]. Mezbaha endüstrisi atıksularının içermiş olduğu kirleticiler nedeniyle arıtılması oldukça güç ve pahalıdır. $\mathrm{Bu}$ atıksuların arıtılması için çeşitli fiziksel, kimyasal ve biyolojik arıtma teknikleri kullanılmaktadır $[4,5,6,7,8]$.

Membran teknolojileri son yıllarda atıksuların ileri arıtılması amacıyla tercih edilmektedir. Bunun nedeni ise, membran proseslerinin diğer prosesler ile karşılaştırıldığında düşük enerji ihtiyacı gerektirmeleri, kesikli ve sürekli işletilebilmeleri, yüksek saflıkta ürün elde edilebilmesi, sıcaklık değişimlerinden fazla etkilenmemeleri, modüler olarak tasarımlarının yapılabilmesi ve fazla yer kaplamaması, kimyasal katkı ihtiyacının olmamasıdır [9].

Endüstriyel atıksu arıtma uygulamalarında basınç sürücülü membran prosesler kullanılmaktadır. Membran malzemelerin ayırma büyüklüklerine göre bu prosesler, mikrofiltrasyon (MF), ultrafiltrasyon (UF), nanofiltrasyon (NF) ve ters osmoz (TO) olmak üzere 4 kategoriye ayrılmaktadır. MF ve UF prosesleri sırasıyla katı/kolloidal parçacıklar ve büyük moleküler ağırlıklı organik maddeler için kullanılmakta iken, NF ve TO prosesleri çözünmüş inorganikler için kullanılmaktadır.

Gürel and Büyükgüngor [10] mezbaha atıksularından nutrient ve organik giderim için MBR reaktörlerin performansını araştırmışlardır. MBR reaktörde UF membran kullanmışlardır. Yapılan çalışmalar sonucunda KOİ, TOK, TN ve TP için giderim verimleri sirasiyla $\% 97,96,44$ ve 65 'dir.

Yordanov, [11] kümes hayvanları mezhaba atıksularının ultrafiltrasyonla arıtımını incelediği çalışmada 25kDa ultrafiltrasyon membran kullanmıştır ve arıtım verimi KOİ ve BOİ5 için \%94 civarında, askıda katı madde giderimi ise \%98'dir. Coşkun vd., [12] kanatlı kesimhane atıksularının membran proseslerle arıtılabilirliğini araştırmışlardır. Membran proseslerde ters osmoz, nanofiltrasyon ve ultrafiltrasyon membranlarını kullanmışlardır. En yüksek KOİ giderimi \%90 NF için, \%97.4 ise RO için elde etmişlerdir. İletkenlik parametresinde de \%51.7 NF için, \%96.6 RO için azaldığını bildirmişlerdir. KOİ ve iletkenlik giderimi açısından UF membranının ön arıtım olarak kullanılması giderim performansını çok etkilemezken membran akıları açısından değerlendirildiğinde UF membranlarının ön arıtım aşaması olarak kullanılmasının oldukça önemli olduğunu bildirmişlerdir. Almandoz et al. [13] mezbaha suları üzerinde MF seramik membranların etkisini araştırmışlardır. $\% 90,63$ KOİ giderimi elde etmişledir..

Türkiye'de ve dünyada çok önemli endüstriyel kirlilik kaynaklarından biri olan mezbahane atıksularının arıtımına ve yönetimine yönelik sınırlı sayıda çalışma bulunmaktadır. Günümüze kadar yapılmış olan çalışmaların pek çoğunun mezbaha atıksularının konvansiyonel (kimyasal ve biyolojik) arıtma prosesleri ile kısmi olarak arıtımı üzerine olup tam bir arıtım prosesi kullanılarak atığın yönetiminde ileri arıtma tekniği olan membran ayırma sistemlerinin kullanımı sınırlı sayıdadır. Bu çalışmanın amacı, mezbaha tesislerinden kaynaklanan yüksek organik yüke sahip atık suyunun arıtılması için geleneksel arıtma yöntemlerinden ziyade bu suyun yeniden kullanımına olanak sağlayabilecek ileri arıtma alternatiflerinden biri olan membran proseslerin performansı değerlendirilmiştir. Bu amaçla, ön arıtım olarak kaba filtreden geçirildikten sonra farklı basınç ve farklı moleküler ağırlık ayırma sınırlarında (MWCO) UF ve NF membranları ile mezbaha tesisi atık suyunun arıtımı gerçekleştirilmiştir.

\section{MATERYAL VE METOD}

\subsection{Membranlar}

Deneylerde kullanılan membranlara ilişkin genel özellikler Tablo 1'de verilmiştir.

Tablo 1. Deneyler sırasında kullanılan membranlar ve özellikleri

\begin{tabular}{ccllll}
\hline Membran tipi & $\begin{array}{c}\text { MWCO } \\
\text { /Gözenek boyutu }\end{array}$ & Polimer & Üretici & İsim & Boyut \\
\hline UF & $10 \mathrm{kDA}$ & Polietersülfon (PES) & GE & PW & $47 \mathrm{~mm}$ \\
UF & $50 \mathrm{kDA}$ & Poliakrilonitril (PAN) & GE & MW & $47 \mathrm{~mm}$ \\
NF & $150-300 \mathrm{DA}$ & Poliamid-TFC & GE & DL & $47 \mathrm{~mm}$ \\
\hline
\end{tabular}

\subsection{Deneysel Çalışma Düzeneği}

Mezbaha atıksularının membran deneyleri Şekil 1'de verilen $300 \mathrm{~mL}$ kapasiteli Sterlitech marka HP4750 karıștırmalı filtrasyon ünitesinde gerçekleştirilmiştir. Deneyler oda sicaklığında $\left(25 \pm 2^{\circ} \mathrm{C}\right)$ gerçekleştirilmiştir. Filtrasyon ünitesine atıksu doldurulduktan sonra basınç ayarlaması (3-5-8-10 bar) yapılmış ve membran yüzeyindeki atıksuyun homojen olmasını sağlamak için fitrasyon ünitesi manyetik karıştırıcının üzerine yerleştirilmiştir. Sistemde istenen membran geçiş basıncı, modüle doğrudan beslenen azot gazı ile sağlanmıştır. Bu amaçla düzeneğe bir adet azot tüpü bağlanarak; modüle gaz geçişini sağlayan azot gazı iletim ve tahliye hattına bağlı bir adet basınç açma ve bir adet basınç ayarlama vanası vasıtasıyla güvenli işletim yerine getirilmiştir. Permeat örnekleri 50, 75 ve $100 \mathrm{~mL}$ 'lik mezürlerde toplanmıştır. Atıksu membrandan geçirilmeden 
önce ve geçirildikten sonra saf su akılarına bakılmıştır. Membranlardaki akı kayıpları, toplam akı kaybı, kirlenmeden kaynaklanan akı kaybı ve konsantrasyon polarizasyonundan kaynaklanan akı kaybı olmak üzere hesaplanmıştır.

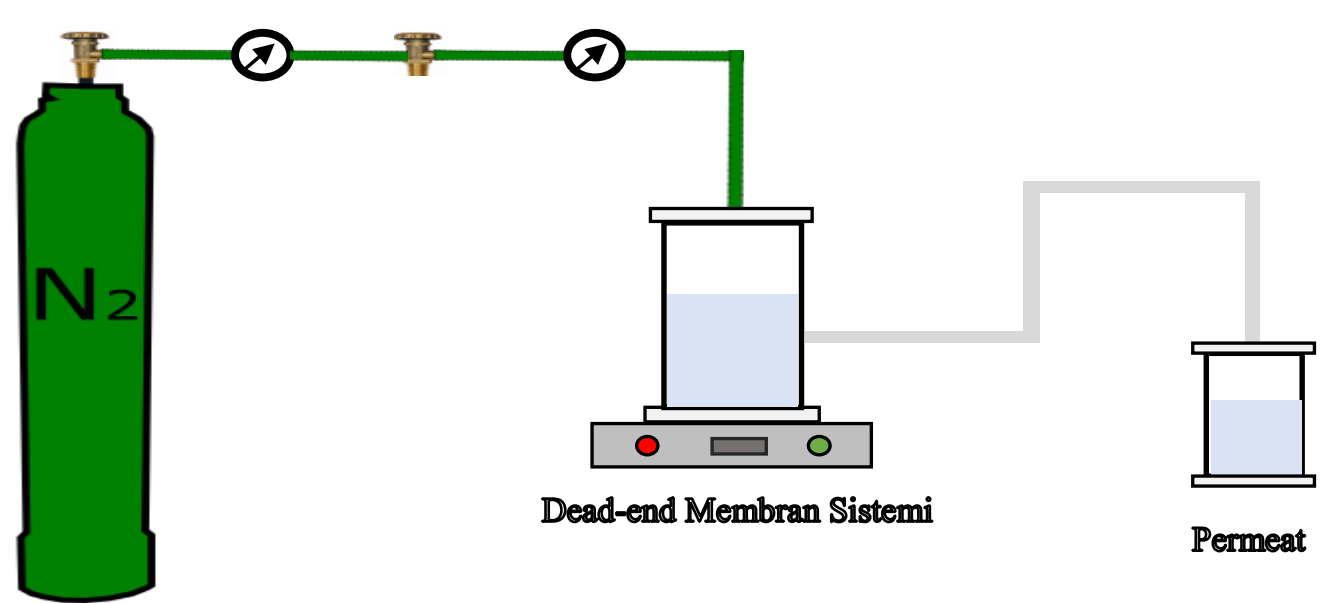

Şekil 1. Deneylerde kullanılan membran düzeneği

\subsection{Mezbaha Atıksuyu}

Mezbaha tesisi atıksuyu örnekleri Niğde Belediyesi Mezbahanesi’nden temin edilmiş olup atıksu karakterizasyon çalışmaları yapılmıştır. Yapılan deneyler neticesinde mezbaha atıksuyu karakterizasyonu Tablo 2'de verilmiştir.

Tablo 2. Mezbaha endüstrisi atıksu karakterizasyonu

\begin{tabular}{ll}
\hline Parametre & Sonuç \\
\hline pH & 7,11 \\
Bulanıklık (NTU) & 92,4 \\
KOİ (mg/L) & 3800 \\
TOK (mg/L) & 1595,5 \\
İletkenlik (mS/cm) & 4,32 \\
AKM (mg/L) & 188 \\
TP $(\mathbf{m g} / \mathbf{L})$ & 11,7 \\
\hline
\end{tabular}

\subsection{Analitik Yöntemler}

Deneysel çalışmalar sonrasında elde edilen her bir numune analizi yapılmak üzere $+4{ }^{\circ} \mathrm{C}$ 'de buzdolabında bekletilmiştir. Bütün analizler Standart Metotlar (SM)'a [14] göre yapılmıştır. Kimyasal oksijen ihtiyacı (KOİ) kapalı reflux titrimetrik yönteme göre gerçekleştirilmiştir (SM 5220 C). AKM ve iletkenlik analizleri sırasıyla SM 2540 D ve SM 2510 B metodlarına göre yapılmıştır.

\section{BULGULAR VE TARTIŞMA}

10 kDA UF, 50 kDA UF ve 150-300 DA NF membranlarının farklı permeat hacimlerine ait değerler Şekil 2'de verilmiştir. $50 \mathrm{~mL}$ permeat toplandığında kaydedilen değer, çalışmanın yaklaşık ilk saatleri arasındaki ortalama akı değeridir. Görüldüğü üzere çalışma basıncı arttıkça, akı artmaktadır. $10 \mathrm{kDA}$ UF membranda 3 barda yapılan deneylerde $50 \mathrm{~mL}$ ile $100 \mathrm{~mL}$ toplanan permeatın akısı arasındaki fark diğer membran ve basınçlardan daha fazladır. Bunun nedeni de PES membranının hidrofobik olması ve kimyasal aşınmaya karşı daha dirençli olmasından dolayı PES ve PAN membranları arasındaki akı farkı gözlenmiştir [15]. 2 farklı UF membranıyla ve iki farklı basınçta yapılan deneyler karşılaştırıldığında 50 kDA UF membranında ve 5 bar 
Ö. B. Gökçek

basınçta elde edilen akı değerleri daha yüksektir. Aynı şekilde 150-300 DA NF membranında da basınç 8 bardan 10 bara çıkarıldığında elde edilen akı değerleri yükselmiştir. Buradan hareketle uygulanan basınç arttıkça akı artmaktadır. Filtrasyonun itici gücünün basınç olması nedeni ile basınç arttıkça akının artması olası görülmektedir. Kaleli, [9] yaptığı çalışma da benzer şekilde basınç değeri arttıkça akı değeri yükselmiştir. Oktav Akdemir ve Özer [16] yaptıkları çalışmada 2 farklı UF membranı ve NF membranı kullanarak basınç, besleme debisi ve membran tipinin süzüntü akısı ve membran kirlenmesine olan etkilerini incelemişlerdir. Basınç ve debideki artışın süzüntü akısını arttırdığını belirtmişlerdir.

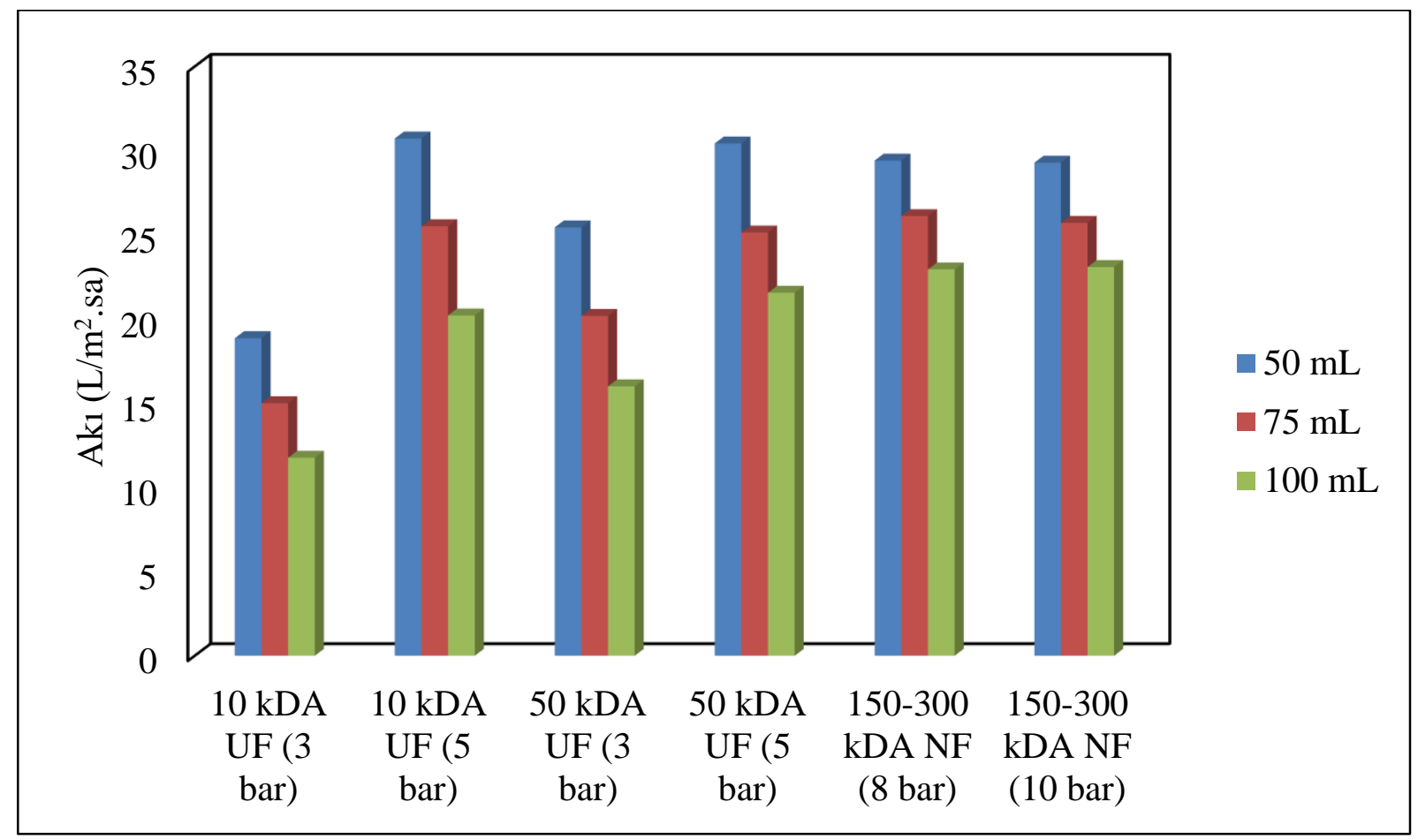

Şekil 2. Farklı basınçlara bağlı akı değerleri

Akı kayıpları, toplam akı kaybı, kirlenmeden kaynaklanan akı kaybı ve konsantrasyon polarizasyonundan kaynaklanan akı kaybı olmak üzere ayrı ayrı hesaplanarak belirlenmiştir. Akı kayıplarının hesaplanabilmesi için, temiz membranın saf su akısının $\left(\mathrm{J}_{0}\right)$, atıksuyu geçirildikten sonra oluşan atıksu akısının $(\mathrm{J})$, kirlenmiş membranın saf su akısının $\left(\mathrm{J}_{\mathrm{f}}\right)$ bilinmesi gereklidir. Deneyler neticesinde hesaplanan akı kaybı değerleri Tablo 4'de verilmektedir.

Tablo 3. Kullanılan membranların atıksu geçirilmesi sonucunda meydana gelen akı kayıpları

\section{Akı kaybı (\%)}

Membran tipi

$\begin{array}{cr}\text { Topla } & \text { Kirlenmeden } \\ \text { m akı } & \begin{array}{c}\text { kaynaklanan akı } \\ \text { kaybı }\end{array} \\ \left(\mathbf{J}_{0}-\mathbf{J} / \mathbf{J}_{0}\right) & \text { kaybı }\left(\mathbf{J}_{0}-\mathbf{J}_{\mathbf{f}} / \mathbf{J}_{0}\right)\end{array}$

Konsantrasy

on

polarizasyondan

kaynaklanan akı

kaybı ( $\left.\mathbf{J}_{\mathbf{f}}-\mathbf{J} / \mathbf{J}_{0}\right)$

\begin{tabular}{llll}
\hline 10 kDa UF (3 bar) & 95,44 & 72,73 & 22,65 \\
10 kDa UF (5 bar) & 96,55 & 80,31 & 16,24 \\
50 kDA UF (3 bar) & 92,83 & 11,74 & 81,09 \\
50 kDA UF (5 bar) & 94,59 & 83,53 & 11,06 \\
$150-300$ DA NF (8 bar) & 46,18 & 7,8 & 38,38 \\
$150-300$ DA NF (10 bar) & 46,48 & 4,06 & 42,42 \\
\hline
\end{tabular}


10 kDa UF membranının farklı basınçtaki akı kayıplarına bakıldığında toplam akı kayıplarının birbirine yakın olduğu fakat 5 barda gerçekleştirilen deneylerdeki akı kaybına baktığımızda kirlenmeden kaynaklanan akı kaybının konsantrasyon polarizasyonundan kaynaklanan akı kaybından daha çok olduğu görülmektedir. UF membranları ile yapılan deneylerden elde edilen toplam akı kayıplarının NF membranı ile elde edilen toplam akı kayıplarından daha yüksek olduğu belirlenmiştir. Ayrıca NF membranlarında hem 8 bar hem de 10 barda yapılan deneylerde konsantrasyon polarizasyonundan kaynaklanan akı kaybının daha yüksek olduğu belirlenmiştir. UF membranlarında ise 3 barda çalışılan $50 \mathrm{kDA}$ UF membranı hariç tüm membranlarda toplam akı kaybının büyük kısmının kirlenmeden kaynaklandığı belirlenmiştir.

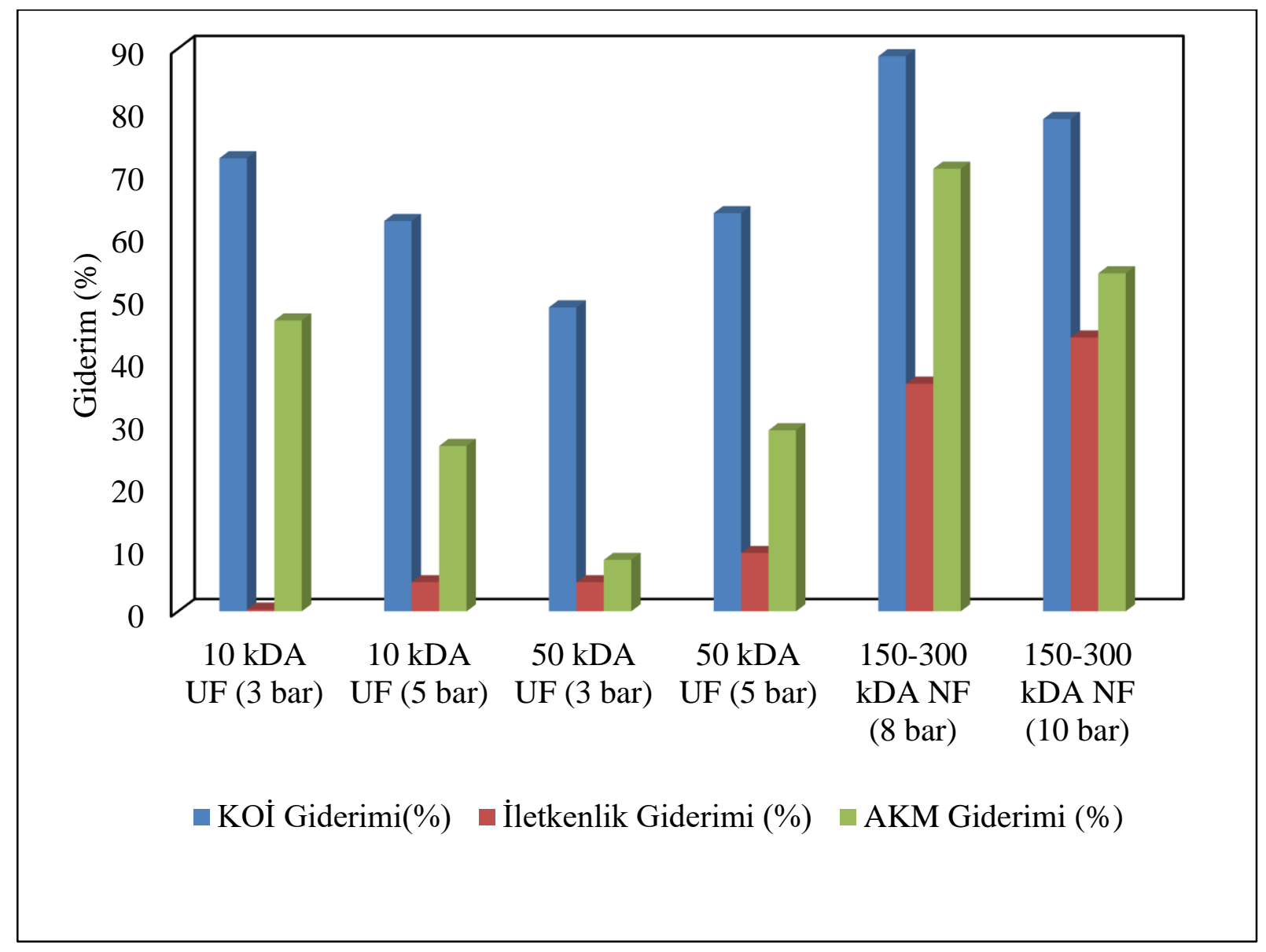

Şekil 3. Kullanılan membranların kirletici performansları

Şekil 3'de verilen 10 kDA UF, 50 kDA UF ve 150-300 DA NF membranlarının KOİ, İletkenlik ve AKM giderimleri karşılaştırıldığında gözenek boyutu küçüldükçe KOİ gideriminin arttığı gözlenmektedir. Bunun en önemli nedeni küçük gözenek boyutuna sahip membranlarda çok daha iyi tutulmanın gerçekleşmesi olarak açıklanabilir. Küçük gözenek boyutuna sahip membranlarda oluşan kek formu da küçük olduğu için tutulma daha iyi olmaktadır. Coşkun vd., [12] kanatlı kesimhane atıksularının ters osmoz, nanofiltrasyon ve ultrafiltrasyon membranlarını kullanarak arıtımını yaptıkları çalışmada benzer olarak en yüksek KOİ giderimi \%90 NF için, \%97.4 ise RO için elde etmişlerdir. İletkenlik parametresinde de \%51.7 NF için, \%96.6 RO için azaldığını bildirmişlerdir. Yordanov, [11] kümes hayvanları mezhaba atıksularının 25 kDA ultrafiltrasyon membranı ile arıtımını incelediği çalışmada \%94 KOİ giderimi, \%98 askıda katı madde giderimi elde etmişlerdir. Aydıner vd., [17] yaptıkları çalışmada da UF ve NF membranların KOİ giderimleri karşılaştırıldığında NF membranının KOİ gideriminin UF membranına kıyasla çok yüksek olduğu belirtilmektedir. Benzer şekilde Elcik vd. [18] yaptıkları çalışmada UF ve NF membranları kullanarak evsel atıksuların arıtılmasını incelemişlerdir. NF membranı KOİ giderim veriminin UF membranından daha yüksek olduğunu belirtmişlerdir. Shih and Kozink [19] kümes hayvanlarının ultrafiltrasyonla gideriminin çalıştıkları çalışmada \%85 toplam katı, \%95 KOİ giderim verimi elde etmişlerdir.

50 kDA PAN membranda basınç artışıyla KOİ, iletkenlik ve AKM giderim veriminde artış gözlenirken $10 \mathrm{kDA}$ PES ve 150-300 DA NF membranlarda tam tersine basıncin artmasiyla KOİ ve AKM parametrelerinin gideriminde azalma 
gözlenmektedir. Göksel [20] yaptıkları çalışmada ağaç endüstrisi atıksularının membran prosesler ile artılabilirliğini incelemişlerdir. Bu amaçla farklı gözenek ebatlarına $(50,100,200 \mathrm{~nm})$ sahip olan membranların farklı basınçlar altında KOİ giderme performansını değerlendirmişlerdir. Basınç arttıkça KOİ giderim veriminin azaldığını belirtmişlerdir. Oktav Akdemir ve Özer [21] yılında yaptıkları çalışmada zeytinyağı yağı atıksuyunun 2 farklı UF membranı farklı basınçlarda arıtımını gerçekleştirmişlerdir. Düşük basınçlarda KOİ gideriminin daha iyi olduğu sonucuna varmışlardır.

\section{SONUÇLAR}

Literatürde, mezbaha atıksularının arıtımında membran sistemlerinin kullanılmasıyla ilgili çok az sayıda araştırma bulunmaktadır. Bu çalışmada, bir mezbaha atıksuyunda denemesi yapılan farkli tip ve özellikte membranların, kirletici giderim performansları, membran akıları ve akı kayıpları araştırılmıştır. Yapılan çalışmadan genel olarak, aşağıdaki sonuçlar elde edilmiştir:

(1) $10 \mathrm{kDA}$ UF, $50 \mathrm{kDA}$ UF ve 150-300 DA NF membranlarının farklı basınçlarda 50, 75 ve $100 \mathrm{~mL}$ permeat hacimlerinin toplandığı deneyler yapılmıştır. $50 \mathrm{~mL}$ permeat toplandığında kaydedilen değer, çalışmanın yaklaşık ilk saatleri arasındaki ortalama akı değeri olmuştur. Membranlara uygulanan basınç arttıkça, akı artmıştır. 2 farklı UF membranıyla ve iki farklı basınçta yapılan deneyler karşılaştırıldığında $50 \mathrm{kDA}$ UF membranında ve 5 bar basınçta elde edilen akı değerleri daha yüksektir. Buradan hareketle gözenek çapı küçüldükçe ve uygulanan basınç arttıkça akı artmaktadır. Aynı şekilde 150-300 DA NF membranında da basınç 8 bardan 10 bara çıkarıldığında elde edilen akı değerleri yükselmiştir.

(2) UF membranları ile yapılan deneylerden elde edilen toplam akı kayıplarının NF membranı ile elde edilen toplam akı kayıplarından daha yüksek olduğu belirlenmiştir. Ayrıca NF membranlarında hem 8 bar hem de 10 barda yapılan deneylerde konsantrasyon polarizasyonundan kaynaklanan akı kaybının daha yüksek olduğu belirlenmiştir.

(3) 10 kDA UF, 50 kDA UF ve 150-300 DA NF membranlarını KOI, İletkenlik ve AKM giderimleri karşılaştırıldığında gözenek boyutu küçüldükçe KOİ gideriminin arttı̆̆ gözlenmiştir. 50 kDA PAN membranda basınç artışıyla KOİ, iletkenlik ve AKM giderim veriminde artış gözlenirken 10 kDA PES ve 150-300 DA NF membranlarda tam tersine basıncın artmasıyla KOİ ve AKM parametrelerinin gideriminde azalma gözlenmiştir.

\section{KAYNAKLAR}

[1] E. Gürtekin, "Mezbaha Atıksuyunun Koagülasyon/Flokülasyon ardışık Kesikli Reaktör (AKR) Yöntemiyle Arıtılması, Uludağ Üniversitesi Mühendislik-Mimarlık Fakültesi Dergisi, vol. 14, no. 2, pp. 131-136. 2009.

[2] D.I. Masse, and L. Masse, "Characterization of wastewater from hog slaughterhouses in Eastern Canada and evaluation of their in-plant wastewater treatment systems", Canadian Agricultural Engineering, vol. 42, no. 3, pp. 139-146, 2000.

[3] S. Satyanarayan, Ramakant and A.P. "Vanerkar, Conventional approach for abattoir wastewater treatment", Environmental Technology, vol. 26, pp. 441-447, 2005.

[4] M.I. Aguilar, J. Saez, M. Llorens, A. Soler, J.F. Ortuno, V. Meseguer, and A. Fuentes, "Improvement of coagulationflocculation process using anionic polyacrylamide as coagulant aid", Chemosphere, vol. 58, pp. 47-56, 2005.

[5] N.Z., Al-Mutairi, M.F., Hamoda, I., Al-Ghusain, "Coagulant selection and sludge conditioning in a slaughterhouse wastewater treatment plant" Bioresource Technolgy, vol. 95, pp. 115-119, 2004.

[6] M.I., Aquilar, J., Saez, M., Llorens, A., Solar, J.F., Ortuno, "Microscopic observation of particle reduction in slaughterhouse wastewater by coagulation - flocculation using ferric sulphate as coagulant and different coagulant aids", Water Research, vol. 37, pp. 2233-2241, 2003.

[7] K., Subramaniam, P.F., Greenfield, K.M., Ho, M.R., Johs, J., Keller, "Efficient biological nutrient removal in high strength wastewater using combined anaerobic-sequencing batch reactor treatment ", Water Science and Technology, vol. 36, no. 2-3, pp. 225-228, 1994.

[8] I., Ruiz, M., Veiga, P., De Santiago, R., Blazquez, "Treatment of slaughterhouse wastewater in a UASB reactor and an anaerobic filter", Biosource Technology, vol. 60, pp. 251-258, 1997.

[9] B., Kaleli, Atıksuların İleri Arıtımında Membran Proseslerinin Kullanımının Araştırılması, İstanbul Üniversitesi Fen Bilimleri Enstitüsü Yüksek Lisans Tezi, 2006.

[10]L., Gürel, H., Büyükgüngör, "Treatment of slaughterhouse plant wastewater by using a membrane bioreactor", Water Science and Technology, vol. 64, no. 1, 2011. 
[11] D., Yordanov, "Preliminary study of the efficiency of ultrafiltration treatment of poultry slaughterhouse wastewater", Bulg. J. Agric. Sci. Vol. 16, no. 6, pp. 700-704, 2010.

[12] T. Coskun, E. Debik, H.A. Kabuk, N.M. Demir, İ. Baştürk, B. Yıldırım, D. Temizel, Ş. Küçük, "Treatment of poultry slaughterhouse wastewater using a membrane process, water reuse, and economic analysis", Desalination and Water Treatment. Vol. 57, pp. 4944-4951, 2016.

[13] Almandoz, M.C., Pagliero, C.L., Ochoa, N.A., Marchese, J.,." Composite ceramic membranes from natural aluminosilicates for microfiltration applications", Ceram. Int. Vol. 41, no. 4, pp. 5621-5633, 2015.

[14] APHA, Standard Methods for the Examination of Water \& Wastewater, twenty-first ed., American Public Health Association (APHA), American Water Works Association (AWWA), Water Environment Federation (WEF), Washington, DC, 2005.

[15] M. E. Paşaoğlu, "Polietersülfon(pes) Ve Poliakrilonitril(pan) Polimerleri Kullanılarak Düz-plaka Membranların Üretimi Ve Uygulamaları”, İstanbul Teknik Üniversitesi, Fen Bilimleri Enstitüsü, 2015.

[16] E. Oktav Akdemir, A. Özer, "Zeytinyağı Endüstrisi Atıksularının Ultrafiltrasyon Ve Nanofiltrasyon Membranlarıyla Arıtılabilirliği”, Deü Mühendislik Fakültesi Fen Ve Mühendislik Dergisi vol. 9, no. 2, pp. 2938, 2007.

[17] C. Aydıner, B., Kırıl Mert, E., Can Doğan, E., Balcı, Y. M., Tilki, Ş., Aksu, A. Y., “Tekstil Yıkama Atıksularından Basınçlı Membran Proseslerle Su Geri Kazanımı Üzerine Membran Türünün Etkisinin Araştırılması”, Uludağ Üniversitesi Mühendislik Fakültesi Dergisi, vol. 21, no. 2, 2016 .

[18] H. Elcik, S. Ö. Çelik, M. Çakmakc1, E. Ünal, B. Kaya, "Farklı Özelliklere Sahip Polimerik Membranlarla Evsel Atıksuların Arıtılması” Nevşehir Bilim Ve Teknoloji Dergisi, vol. 5, no. 2, pp. 104-116, 2016.

[19] J. Shih, and M. B. Kozink, "Ultrafiltration treatment of poultry processing wastewater and recovery of a nutritional by-products". Poultry Science, vol. 59, no. 2, pp. 247-252, 1980.

[20] Z. Göksel, "Çapraz Akışlı Seramik Membran Sistemi İle Ağaç Endüstrisi Atıksularının Geri Kazanımı”, Balıkesir Üniversitesi Fen Bilimleri Enstitüsü Çevre Mühendisliği Anabilim Dalı, 2019.

[21] E. Oktav Akdemir, A. Özer, "Investigation of two ultrafiltration membranes for treatment of olive oil mill wastewater", Desalination, vol. 249, pp. 660-666, 2009. 